\title{
MEAN NUSSELT NUMBER CORRELATION FOR TISE HEATSINK THERMAL DESIGN
}

\author{
A. I. Sato ${ }^{\mathrm{a}}$ ABSTRACT \\ C. A. C. Altemani ${ }^{b}$ \\ and V. L. Scalon \\ ${ }^{a}$ Federal University of the West of Bahia, Bom \\ Jesus da Lapa, Brazil \\ Av. Dr. Manoel Novaes, 1028, Bom Jesus da \\ Lapa - BA \\ ${ }^{\mathrm{b}}$ Mechanical Engineering College, State \\ University of Campinas, Campinas, Brazil; \\ ${ }^{\mathrm{c}}$ Mechanical Engineering Department, São \\ Paulo State University, Bauru, Brazil. \\ andre.sato@ufob.edu.br \\ This work was developed from a review of the technical literature for the \\ thermal design of parallel plates heat sinks with uniform cross section \\ cooled by airflow with the TISE (Top Inlet Side Exit) configuration. Due to \\ an observed lack of agreement of the literature correlations among \\ themselves and also with the available experimental results, numerical \\ simulations were then performed to evaluate the forced convective heat \\ transfer in the channels of these heat sinks with the TISE configuration. The \\ simulations encompassed a range of heatsink airflow rates, considering \\ distinct channel sizes and also the effect of a partial opening for the airflow \\ entrance at the heat sink top. The obtained numerical results were employed \\ to evaluate the average convective heat transfer coefficient inside the \\ heatsink's channels, based on the flow mixed mean temperature. A new \\ empirical correlation was then proposed for the average Nusselt number as \\ a function of the airflow Reynolds number and three dimensionless channel \\ geometric parameters. The new correlation was compared with available \\ experimental data.
}

Received: January 20, 2020

Revised: February 23, 2020

Accepted: May 28, 2020

Keywords: plate fin heatsink; mean Nusselt number; numerical analysis;

forced convection

\section{NOMENCLATURE}

AR Aspect Ratio

C Heat capacitance $\left[\mathrm{W} /{ }^{\circ} \mathrm{C}\right]$

ср Specific heat $\left[\mathrm{J} / \mathrm{kg}{ }^{\circ} \mathrm{C}\right]$

Dhe Exit Hydraulic Diameter [mm]

Dh Inlet Hydraulic Diameter [mm]

$\mathrm{H} \quad$ Fin height [mm]

$\overline{\mathrm{h}} \quad$ Mean convective heat transfer coefficient based on inlet and outlet temperature $\left[\mathrm{W} / \mathrm{m}^{2}\right.$ $\left.{ }^{\circ} \mathrm{C}\right]$

$\overline{\mathrm{h}}_{\mathrm{m}} \quad$ Mean convective heat transfer coefficient based on flow mean temperature $\left[\mathrm{W} / \mathrm{m}^{2}{ }^{\circ} \mathrm{C}\right]$

$\mathrm{k} \quad$ Thermal conductive $\left[\mathrm{W} / \mathrm{m}{ }^{\circ} \mathrm{C}\right]$

$\mathrm{L} \quad$ Fin length [mm]

$\dot{\mathrm{m}} \quad$ Mass flow $[\mathrm{kg} / \mathrm{s}]$

NTU Number of Heat Transfer Units

$\overline{\mathrm{Nu}} \quad$ Mean Nusselt number based on inlet and outlet temperature

$\overline{\mathrm{Nu}}_{\mathrm{m}} \quad$ Mean Nusselt number based on flow mean temperature

Pr Prandtl number

q $\quad$ Heat transfer rate [W]

$\mathrm{Re}_{\mathrm{B}} \quad$ Biber's Reynolds number

$\mathrm{Re}_{\mathrm{s}}^{*} \quad$ Modified Reynolds number

Re Reynolds number

$\mathrm{R}$ Thermal resistance $\left[{ }^{\circ} \mathrm{C} / \mathrm{W}\right]$

$\mathrm{S} \quad$ Fin spacing $[\mathrm{mm}]$ $\mathrm{t} \quad$ Fin thickness [mm]

$\mathrm{T}$ Temperature $\left[{ }^{\circ} \mathrm{C}\right]$

$\Delta \mathrm{T}$ Temperature difference between inlet and exit $\left[{ }^{\circ} \mathrm{C}\right]$

$\Delta \mathrm{Tml}$ Mean logarithmic temperature difference $\left[{ }^{\circ} \mathrm{C}\right]$

U Mean velocity

$\mathrm{x}_{\mathrm{t}} \quad$ Thermal dimensionless length

\section{Greek symbols}

$\varepsilon \quad$ Effectiveness

$v \quad$ Cinematic viscosity $\left[\mathrm{m}^{2} / \mathrm{s}\right]$

$\eta \quad$ Thermal efficiency

\section{Subscripts}

$\begin{array}{ll}0 & \text { Overall efficiency } \\ \text { a } & \text { Air } \\ \text { b } & \text { Heatsink base } \\ \text { c } & \text { Cold side } \\ \text { ch } & \text { Heatsink channel } \\ \text { e } & \text { Exit based } \\ \text { f } & \text { Fin efficiency } \\ \text { i } & \text { Inlet based } \\ \text { R } & \text { Relative }\end{array}$

\section{INTRODUCTION}


Based on the increasing thermal dissipation rates through the years accompanied by a reduction in the available space for heat dissipation inside electronic equipments, there has been a preference in industry to employ parallel plates heat sinks with a top inlet and side exit configuration (TISE)(ISSA; ORTEGA, 2002). This configuration is represented by a fan installed on top of the finned heatsink, its more compact assembly also allows higher air velocities impinging the fins and, by the same time, it is less feasible to bypass flow, as compared to heat sinks with the side inlet and side exit flow configuration (SISE)(JONSSON; MOSHFEGH, 2001).

Although recent researches trends are concerned to micro scales designs based on every year smaller space available(ARIK et al., 2013; COLLA et al., 2017; FABBRI; DHIR, 2005; SAFFARIPOUR; CULHAM, 2010), the evaluation of finned heatsinks or other traditional cooling methods are still of great usage, especially at electronic cooling systems and LED illumination systems cooling(CHENG et al., 2010; DALIANG ZHONG et al., 2010; KOTLAR; SVASTA, 2017; NONNEMAN et al., 2018; WADA et al., 2017; ZHU et al., 2017). In the thermal design of heatsinks, in order to make a proper use of the convective heat transfer coefficient $\overline{\mathrm{h}}_{\mathrm{m}}$ in the heat sink thermal analysis, it is necessary to employ in Eq. (1) the temperature difference which gives rise to the correct heat transfer rate q. For heat sinks with uniform base temperature $\mathrm{T}_{\mathrm{b}}$, it is the logarithmic mean temperature difference expressed by Thus, the resulting heat transfer rate is given by equation below.

$$
\begin{gathered}
\mathrm{q}=\eta_{0} \overline{\mathrm{h}} \mathrm{A}_{\mathrm{t}} \Delta \mathrm{T} \\
\Delta \mathrm{T}_{\mathrm{ml}}=\frac{\left(\mathrm{T}_{\mathrm{b}}-\mathrm{T}_{\mathrm{i}}\right)-\left(\mathrm{T}_{\mathrm{b}}-\mathrm{T}_{\mathrm{e}}\right)}{\ln \left[\left(\mathrm{T}_{\mathrm{b}}-\mathrm{T}_{\mathrm{i}}\right) /\left(\mathrm{T}_{\mathrm{b}}-\mathrm{T}_{\mathrm{e}}\right)\right]} \\
\mathrm{q}=\eta_{0} \overline{\mathrm{h}}_{\mathrm{m}} \mathrm{A}_{\mathrm{t}} \Delta \mathrm{T}_{\mathrm{ml}}
\end{gathered}
$$

The main problem of this approach is the need to obtain the flow's outlet temperature represented by $\mathrm{T}_{\mathrm{e}}$ and which value depends greatly on the heatsink's geometry.

A better procedure to solve this problem was proposed by Webb(2007) andMoffat(2007), avoiding the need to previously evaluate $T_{e}$ to obtain the heat transfer rate q. They analyzed the heat sink as a heat exchanger through the effectiveness ( $\varepsilon$-NTU) method. The heat sink base, assumed isothermal, was associated to a very large thermal capacitance $\left(\mathrm{C}_{\mathrm{h}}\right)$ of the hot fluid. The cold side of the heat exchanger was associated to the heat sink cooling fluid flow, with a thermal capacitance $\mathrm{C}_{\mathrm{c}}$ given by the product $\left(\dot{\mathrm{m}} \mathrm{c}_{\mathrm{p}}\right.$ ) of its mass flow rate and the fluid specific heat $c_{p}$.

This heat exchanger presents a thermal capacitances ratio $\left(C_{r}=C_{c} / C_{h}\right)$ essentially equal to zero and thus the relation between its effectiveness $\varepsilon$ and the number of transfer units NTU is a simple function. The value of NTU may be obtained from Eq. (4) and the effectiveness, in this case, may be obtained from Eq. (5). The convective heat transfer rate between the heat sink and its internal fluid flow can then be obtained from Eq. (6), characterizing a heat sink thermal resistance as presented in Eq. (7).

$$
\begin{gathered}
\text { NTU }=\frac{\eta_{0} \overline{\mathrm{h}}_{\mathrm{m}} \mathrm{A}_{\mathrm{t}}}{\dot{\mathrm{m} \mathrm{c}_{\mathrm{p}}}} \\
\varepsilon=1-\exp (-\mathrm{NTU}) \\
\mathrm{q}=\varepsilon \dot{\mathrm{m}} \mathrm{c}_{\mathrm{p}}\left(\mathrm{T}_{\mathrm{b}}-\mathrm{T}_{\mathrm{e}}\right) \\
\mathrm{R}=\frac{1}{\varepsilon \dot{\mathrm{m}} \mathrm{c}_{\mathrm{p}}}
\end{gathered}
$$

The heat transfer rate (q) expressed by Eq. (6) is based on the convenient temperature difference $\left(\mathrm{T}_{\mathrm{b}}-\mathrm{T}_{\mathrm{e}}\right)$, with the main difference that this procedure makes proper use of the conventional convective heat transfer coefficient $\overline{\mathrm{h}}_{\mathrm{m}}$ and it considers an energy balance for the fluid flow in the heat sink. The expression for $\mathrm{R}$ given by Eq. (7) shows clearly the influences exerted by the mass flow rate $\dot{\mathrm{m}}$ and by the heatsink effectiveness $(\varepsilon)$.

The main purpose of the present work was to obtain a correlation for the average Nusselt number $\overline{\mathrm{Nu}}_{\mathrm{m}}$ for an air-cooled parallel plate heatsink with the TISE configuration. It was based on the flow mixed mean temperature so that the corresponding heat transfer coefficient $\bar{h}_{m}$ could be used directly into the effectiveness method to perform the thermal evaluation of a heat sink as a heat exchanger, as described by Eqs. (4) to (7).

The desired correlation was obtained from numerical simulations of the fluid flow and heat transfer in rectangular channels with three isothermal walls closed by an adiabatic wall. Several geometries were tested, corresponding to distinct heat sink channels. Due to the TISE configuration, the flow entered the channel by an opening in the middle of the top adiabatic wall, directed to the lower wall. From the results, a correlation was proposed for the average Nusselt number $\overline{\mathrm{Nu}}_{\mathrm{m}}$, valid for a range of heatsinks sizes.

\section{CORRELATIONS FOR THE ANALYSIS}

Most investigations related to the thermal design of parallel plates heat sinks employed the convective thermal resistance model. The correlations for predicting the heat transfer coefficient from three distinct investigations will be presented here in order to illustrate their distinct origins. One was based on analytical correlations from the literature, the second 
was based on numerical simulations and the third was based on experiments.

For airflow cooled parallel plates heat sinks with fins of high aspect ratio and the SISE flow configuration, authorsdeveloped an analytical model in the form $\overline{\mathrm{Nu}}=\overline{\mathrm{h}} \mathrm{s} / \mathrm{k}$. Their correlation was obtained as an asymptote from two correlations for the parallel plated channel. One correlation was that for the thermally developed flow and the other was a correlation for the combined entrance problem, both based on flow inlet temperature in the channel. They obtained a composite correlation for $\overline{\mathrm{Nu}}$ as in Eq. (8), where the modified Reynolds number $\left(\operatorname{Re}^{*}\right)$ is defined as in Eq. (9).

$$
\begin{gathered}
\overline{\mathrm{Nu}} \\
=\left[\left(\frac{\operatorname{Re}_{\mathrm{s}}^{*} \operatorname{Pr}}{2}\right)^{-3}\right. \\
\left.+\left(0.664 \sqrt{\operatorname{Re}_{\mathrm{s}}^{*}} \operatorname{Pr}^{1 / 3} \sqrt{1+\frac{3.65}{\sqrt{\operatorname{Re}_{\mathrm{s}}^{*}}}}\right)^{-3}\right]^{-1 / 3} \\
\operatorname{Re}_{\mathrm{s}}^{*}=\operatorname{Re}_{\mathrm{s}} \frac{\mathrm{s}}{\mathrm{L}}
\end{gathered}
$$

In order to account for the fin's temperature distribution on the convective heat transfer, the correlation for $\overline{\mathrm{Nu}}$, obtained for isothermal walls, was corrected by the fin's efficiency. They performed experimental tests with a heatsink and verified that the results agreed with their predictions with a maximum deviation of $6 \%$. Their tests were performed for $8<\mathrm{Re}_{\mathrm{s}}^{*}<40$ and the heat sink channels had a high aspect ratio $\mathrm{AR}=(\mathrm{H} / \mathrm{s})$.

For parallel plates heatsinks cooled by airflow considering the TISE configuration indicated in Figure 1, [16]performed numerical simulations for several rectangular ducts with three isothermal surfaces (associated to the heat sink base and two adjacent fins) closed by one adiabatic surface. An average Nusselt number $(\overline{\mathrm{Nu}})$ for the flow in the fins channel was defined as in Eq. (10).

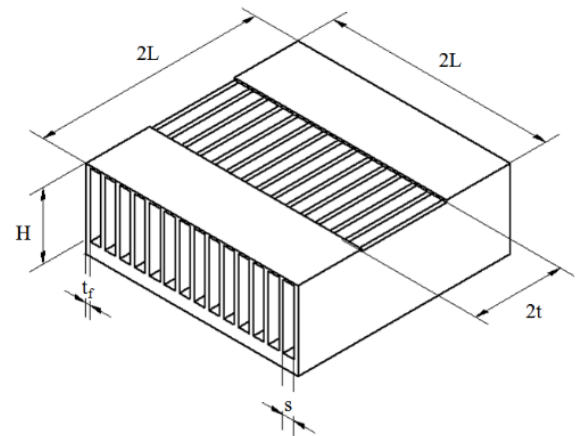

Figure 1. Parallel plates heat sink with the TISE configuration. Source: authors, 2019.

$$
\overline{\mathrm{Nu}}=\frac{\mathrm{q}_{\mathrm{ch}}}{2 \mathrm{~L}(2 \mathrm{H}+\mathrm{s})\left(\mathrm{T}_{\mathrm{b}}-\mathrm{T}_{\mathrm{e}}\right)} \frac{\mathrm{D}_{\mathrm{h}}}{\mathrm{k}_{\mathrm{a}}}
$$

The numerical heat transfer results in the considered fins channels were correlated by Eq. (11), as a function of a single dimensionless length $\left(\mathrm{x}_{\mathrm{t}}\right)$, expressed by Eq. (12). In this equation, the Reynolds number is defined as $\operatorname{Re}_{\mathrm{B}}=\mathrm{U}_{\mathrm{i}} \mathrm{D}_{\mathrm{h}} / \nu_{\mathrm{a}}$. The proposed dimensionless correlation agreed within $16 \%$ with the numerical simulations, performed in the range of $0.001<\mathrm{x}_{\mathrm{t}}<3$.

$$
\begin{aligned}
\overline{\mathrm{Nu}}=\left[\left(6.05 \mathrm{x}_{\mathrm{t}}^{-0.22}\right)^{-3 / 4}\right. & \\
& \left.+\left(0.20 \mathrm{x}_{\mathrm{t}}^{-1.05}\right)^{-3 / 4}\right]^{-4 / 3}
\end{aligned}
$$

$$
x_{t}=\frac{L}{D_{h} \operatorname{Re}_{B}} \frac{H}{t}
$$

Duan and Muzychka(2006) noticed that in the previous model, the definition of $x_{t}$ in Eq. (12) presents the product of the defined Reynolds number $\left(\mathrm{Re}_{\mathrm{B}}\right)$ by the dimensionless ratio $(\mathrm{t} / \mathrm{H})$. When this multiplication is performed, it is equal to a Reynolds number based entirely on the outlet cross section. Thus, the dimensionless length $x_{t}$ and Nusselt Number become independent of the opening width (2t) at the heatsink's inlet. In order to consider the opening width, they proposed a new thermal model, defined by Eq. (13) and based on experimental measurements with several air-cooled parallel plates heat sinks with the TISE configuration. The new correlation, presented by Eq. (14), is a function of the ratio $(\mathrm{t} / \mathrm{L})$ and a new dimensionless length $\left(\mathrm{L}^{*}\right)$ given by Eq. (15).

The Reynolds number appearing in Eq. (16), $\mathrm{Re}=\left(\mathrm{U}_{\mathrm{ch}} \mathrm{D}_{\mathrm{h}} / \mathrm{v}_{\mathrm{a}}\right)$, is defined with the hydraulic diameter $D_{h}$ and the flow average velocity $U_{c h}$ at the heat sink outlet cross section. The correlation was developed for laminar flow between the heat sink channels, in the range $\mathrm{Re}<1200$. Duan and Muzychka(2006)also conducted experimental tests for four distinct parallel plates heat sink geometries with the TISE configuration and for each heatsink, the experimental results for the average Nusselt number $\overline{\mathrm{Nu}}$ were obtained at seven different velocities and six distinct widths of the top inlet.

$$
\begin{gathered}
\overline{\mathrm{Nu}}=\frac{\mathrm{q}_{\mathrm{ch}}}{4 \mathrm{LH}\left(\mathrm{T}_{\mathrm{b}}-\mathrm{T}_{\mathrm{e}}\right)} \frac{\mathrm{D}_{\mathrm{h}}}{\mathrm{k}_{\mathrm{a}}} \\
\overline{\mathrm{Nu}}=\frac{0.54-0.1 \frac{\mathrm{t}}{\mathrm{L}}}{\sqrt{\mathrm{L}^{*}}} \\
\mathrm{~L}^{*}=\frac{\mathrm{L}}{\mathrm{D}_{\mathrm{h}} \operatorname{RePr}}
\end{gathered}
$$




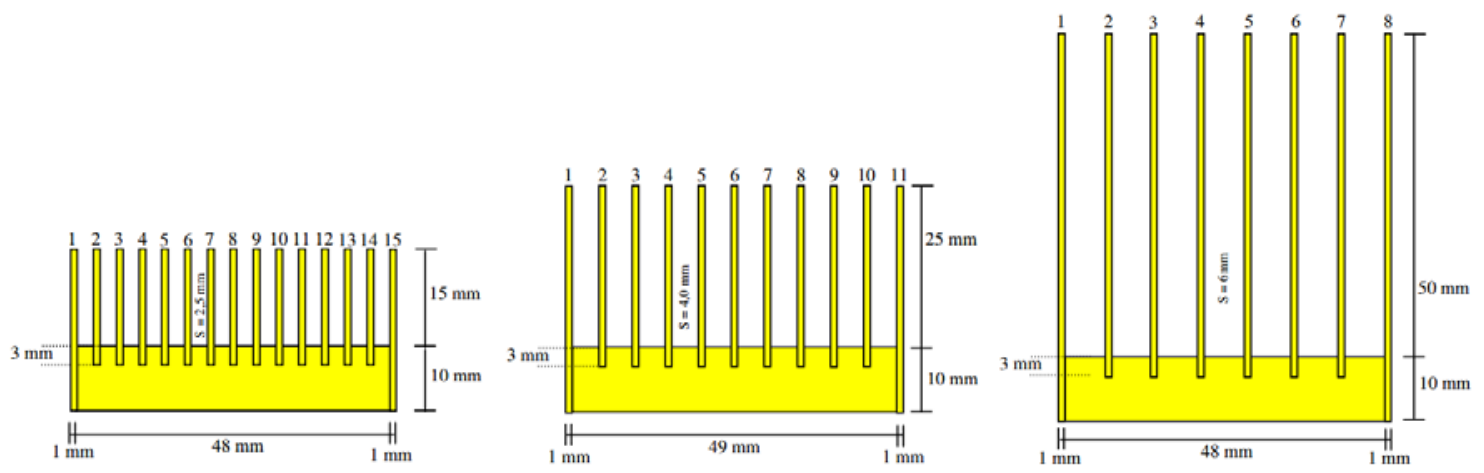

(a)

(b)

(c)

Figure2. Heatsinks (a) I, (b) II and (c) III. Source: Souza(2005).

Researches made by Webb(2007) and Moffat (2007)have indicated the correctness and convenience of using the heat exchanger model for the thermal analysis of heat sinks, instead of using the simple thermal resistance model. The effectiveness method may be applied for heat sinks, as described by Eqs. (4) to (7).

\section{NUMERICAL SIMULATIONS}

The numerical simulations were performed using the PHOENICS (@2009 CHAM Ltd.) software, which uses the finite volume method for the numerical solution of the partial differential equations that represent the principles of mass conservation, linear momentum (Navier-Stokes) and energy.

For the turbulence modeling, the method of zero equations was adopted, based on the velocity profile close to the wall. An algorithm for coupling the velocity and pressure fields is usual. In the computational package used, the algorithm used is called SIMPLEST.

The scheme adopted for the treatment of the convective and diffusive terms of the momentum and energy conservation equations is called a hybrid approach. The computer simulations were performed on a computer with an AMD processor of 8 physical cores, 16 GB of RAM and a video card with 1 GB of dedicated memory.

Initially, threeheatsinks, with the dimensions expressed in Table 1, were simulated with the TISE configuration by varying the mass flow rate, the air temperature at the inlet, the temperature of the heatsink base and the opening width.Figure 2 presents comparative cross-sections to the fins of the three sinks.

Table 1. Channel's dimensions.

\begin{tabular}{ccccc}
\hline Heatsink & $\begin{array}{c}\mathrm{H} \\
(\mathrm{mm})\end{array}$ & $\begin{array}{c}\mathrm{L} \\
(\mathrm{mm})\end{array}$ & $\begin{array}{c}\mathrm{S} \\
(\mathrm{mm})\end{array}$ & $\begin{array}{c}\mathrm{t} / \mathrm{L} \\
(\%)\end{array}$ \\
\hline I & 15 & 50 & 2.5 & $0.2,0.4,0.6,1$ \\
II & 25 & 50 & 4.0 & $0.2,0.4,0.6,1$ \\
III & 50 & 50 & 6.0 & $0.2,0.4,0.6,1$ \\
\hline
\end{tabular}

Source: authors, 2019.
Figure 3 shows the expanded domain model without regard to fin thickness as it was considered being an isothermal plate. The domain has been extended by 50 millimeters along the $\mathrm{x}$-direction from the heatsink output and $50 \mathrm{~mm}$ in the $\mathrm{z}$ direction from the input and the heatsink base. The increase of the domain in the upper part of the channel allows the flow to develop a non-uniform profile on the inlet cross section.

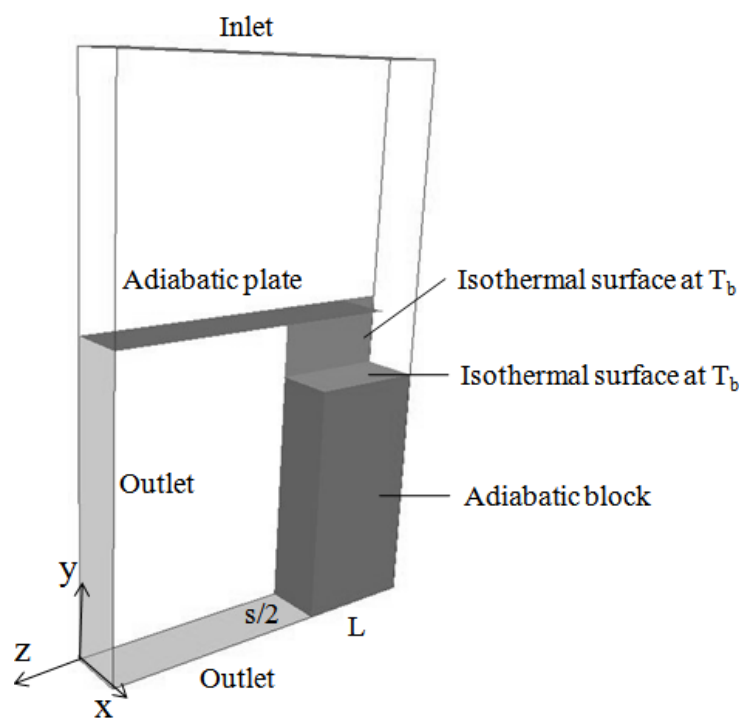

Figure3. Expanded Model of the channel. Source: authors, 2019.

Uniform surface temperature was imposed on the top and base surfaces of the channel. With such an approach, these models had unitary fin efficiency. For practical applications, the value of the convective coefficient obtained by the simulations should be multiplied by the fin efficiency estimate.

The air intake in the calculation domain was specified as being of uniform speed profile and the heat transfer problem was treated as a permanent regime. With smaller and larger Reynolds numbers, the numerical convergence of the results was studied and the convective heat transfer rate variation with 
the mass flow was used to evaluate the independence of the results with the numerical mesh.

The properties of the air flow were considered with the mean fluid temperature between the inlet temperatures and the outlet section of the channel. The thermal conductivity of the aluminum sinks was set at $237 \mathrm{~W} / \mathrm{m}^{2}$.

In the configuration with total opening of the top area of the heatsinks $(t=50 \mathrm{~mm})$, five different air mass flows were simulated. In the configurations with smaller openings $(\mathrm{t}=30 \mathrm{~mm}, \mathrm{t}=20 \mathrm{~mm}, \mathrm{t}=10$ $\mathrm{mm})$, six different air flows were simulated.

The simulations were carried out initially with a set of distinct numerical meshes for each of the three domain models considered, in order to obtain virtually independent results of the mesh. The numerical meshes selected were those that presented results with deviations less than $5 \%$ of those obtained with the most refined mesh.

The mesh contained a concentration of elements in the region close to the walls due to the higher gradients of velocity and temperature of the flow, as well as in the region of the flow in the channel, as shown, for example, in Figure 4. In this case, the mesh with 65500 elements was selected.
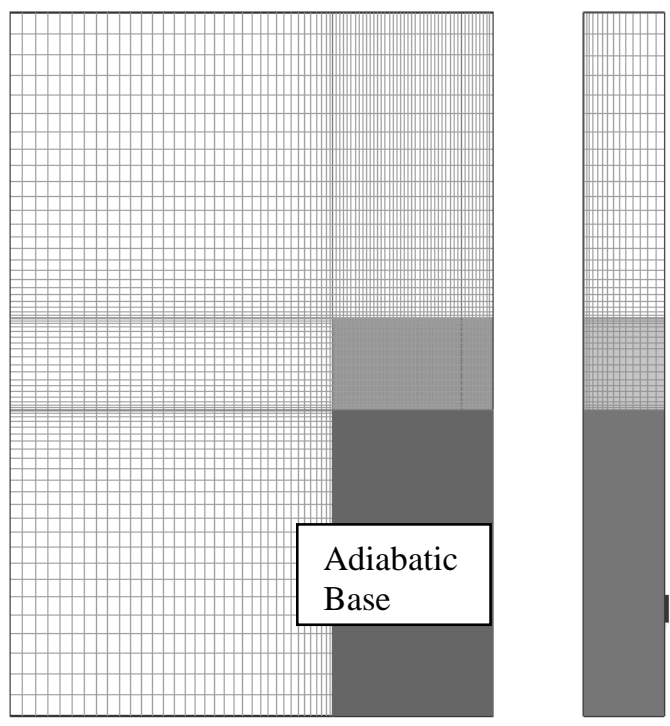

Figure 4. Mesh structure and boundary layer refinement Heatsink I with $10 \mathrm{~mm}$ opening. Source: authors, 2019.

Table 2 presents the number of elements in each model.The numerical simulations considered the fluid flow and convective heat transfer in one channel of a parallel plates heat sink with the TISE configuration. The channel geometry was defined by its length (2L) equal to the heat sink length and by its cross section had the fins spacing $(\mathrm{s})$ and the fins height $(\mathrm{H})$.

The channel had an opening of width (2t) centered along the top wall length for the fluid flow inlet. The flow inlet cross section at the top of the channel was equal to $(2 \mathrm{t} \times \mathrm{s})$ and the flow outlet occurred at both sides of the channel, each one with a cross section ( $\mathrm{H} \mathrm{x} \mathrm{s}$ ).

Table 2. Number of elements in each heatsink.

\begin{tabular}{cccccc}
\hline Heatsink & $\mathrm{t}[\mathrm{mm}]$ & $\begin{array}{c}\mathrm{N}^{\circ} \text { of } \\
\text { Elements }\end{array}$ & $\mathrm{X}$ & $\mathrm{Y}$ & $\mathrm{Z}$ \\
\hline \multirow{3}{*}{$\mathrm{I}$} & 50 & 78750 & 75 & 15 & 70 \\
& 30 & 81900 & 78 & 15 & 70 \\
& 20 & 81900 & 78 & 15 & 70 \\
& 10 & 81900 & 78 & 15 & 70 \\
\hline \multirow{3}{*}{ II } & 50 & 122850 & 78 & 15 & 105 \\
& 30 & 126000 & 80 & 15 & 105 \\
& 20 & 133875 & 85 & 15 & 105 \\
& 10 & 133875 & 85 & 15 & 105 \\
\hline \multirow{3}{*}{ III } & 50 & 187000 & 85 & 20 & 110 \\
& 30 & 209000 & 95 & 20 & 110 \\
& 20 & 209000 & 95 & 20 & 110 \\
& 10 & 209000 & 95 & 20 & 110 \\
\hline
\end{tabular}

Source: authors, 2019.

Considering the flow and thermal symmetry, the computational domain was reduced to a quarter of the fins channel. Two symmetry planes were considered: one at half of the channel length $(2 \mathrm{~L})$ and the other at half of its width $\mathrm{s}$. The channel wall at the heat sink base and the two adjacent lateral walls were considered isothermal, while the top wall was assumed adiabatic. This procedure is equivalent to the consideration of the two lateral fins with efficiency $\eta_{\mathrm{f}}=1$ and it was used previously byTeertstra, Yovanovich and Culham (2000) and by Biber (1997). For heat sinks with fins efficiency $\eta_{\mathrm{f}}<$ 1 , the heatsink's overall surface efficiency $\eta_{0}$ may be evaluated and replaced in Eq. (5) to obtain the NUT.

The simulations were performed for several heat sink channels, described as channels I to VII, in the search for a single correlation for the average Nusselt number $\overline{\mathrm{Nu}}_{\mathrm{m}}$. Channels I, II and III were simulated with the top inlet opening (2t) varying from $20 \%$ to $100 \%$ of the channel length $(2 \mathrm{~L})$. The airflow rate was varied for each channel configuration and its properties in each test were adjusted for the average temperature between the uniform inlet flow temperature $\left(T_{i}\right)$ and the numerically evaluated mixed mean flow temperature at the heat sink outlet cross section $\left(\mathrm{T}_{\mathrm{e}}\right)$.

For the numerical tests, the three isothermal channel walls were considered in the range from $42^{\circ} \mathrm{C}$ to $45^{\circ} \mathrm{C}$, while the airflow inlet uniform temperature varied from $22^{\circ} \mathrm{C}$ to $25^{\circ} \mathrm{C}$.

With this range of temperatures imposed as boundary conditions, the resulting average mixed mean temperature of the airflow was around $30^{\circ} \mathrm{C}$. A total of 68 simulations were performed with heatsinks I, II and III and Table 3 presents their dimensions and the investigated values of $(\mathrm{t} / \mathrm{L})$ and mass flow rates. 
The simulations for each of the channels IV to VII were performed for a single value of the dimensionless opening $(\mathrm{t} / \mathrm{L})$ and for two mass flow rates. These channels were selected to extend the knowledge to obtain a general correlation for the average Nusselt number for this type of heat sink.

Table 3. Dimensions and numerical tests for channels I, II and III.

\begin{tabular}{ccccc}
\hline Dimension & $\begin{array}{c}\mathrm{H} \\
(\mathrm{mm})\end{array}$ & $\begin{array}{c}2 \mathrm{~L} \\
(\mathrm{~mm})\end{array}$ & $\begin{array}{c}\mathrm{s} \\
(\mathrm{mm})\end{array}$ & $\begin{array}{c}\text { Mass flow } \\
\text { rate } \\
(\mathrm{kg} / \mathrm{s})\left(10^{-4}\right)\end{array}$ \\
\hline Channel I & 15 & 50 & 2.5 & 0.26 to 1.9 \\
Channel II & 25 & 50 & 4 & 0.42 to 2.8 \\
Channel III & 50 & 50 & 6 & 0.50 to 4.0 \\
\hline
\end{tabular}

Source: authors, 2019.

The Reynolds number Re at the flow inlet was selected to represent the air flow in the channel also due to the fact that, as the airflow rate increases, the outflow tends to concentrate near the bottom of the channel, while the upper region of the outlet cross section may eventually present a recirculation zone. As a consequence, a Reynolds number evaluated at the outlet cross section may not realistically characterize the flow in the channel. Figure 5 illustrates the flow concentration at the bottom of the channel, as evaluated for channel I, with $(\mathrm{t} / \mathrm{L})=40 \%$ and for $\mathrm{Re}=7685$.

The numerical results for the average Nusselt number $\overline{\mathrm{Nu}}_{\mathrm{m}}$ will be presented as functions of the Reynolds number defined at the heat sink flow inlet cross section, as:

$$
\mathrm{Re}=\frac{\mathrm{U}_{\mathrm{i}} \mathrm{D}_{\mathrm{he}}}{\mathrm{v}_{\mathrm{a}}}
$$

In Eq. (16), $U_{i}$ is the uniform flow inlet velocity, $D_{h}$ is the hydraulic diameter at the channel inlet cross section, $D_{\text {he }}=4 s t /(s+2 t)$ and $v_{a}$ is the air kinematic viscosity.

The convective heat transfer rate $\mathrm{q}$ from the channel to the airflow was obtained from the software and its value was used to evaluate the airflow mixed mean temperature $\mathrm{T}_{\mathrm{e}}$ at the channel outlet by an energy balance, as indicated in:

$$
\mathrm{T}_{\mathrm{e}}=\frac{\mathrm{q}}{\dot{\mathrm{m} c \mathrm{p}}}+\mathrm{T}_{\mathrm{i}}
$$

The evaluated $T_{e}$ was then employed to obtain the logarithmic mean temperature difference $\Delta \mathrm{T}_{\mathrm{lm}}$ together with the specified values of the base $\left(T_{b}\right)$ and the uniform inlet airflow $\left(\mathrm{T}_{\mathrm{e}}\right)$ temperatures, as in Eq. (2).

The average heat transfer coefficient $\overline{\mathrm{h}}_{\mathrm{m}}$ in the fins channel was obtained as in Eq. (3), from the convective heat transfer rate $\mathrm{q}$ and the logarithmic mean temperature difference $\Delta \mathrm{T}_{\mathrm{lm}}$ and also from the total heat transfer area of the fins channel, $A_{t}=$ $(2 \mathrm{~L}(\mathrm{~s}+2 \mathrm{H}))$, since it was considered isothermal.

An average Nusselt number $\overline{\mathrm{Nu}}_{\mathrm{m}}$ was defined using the same characteristic dimension of the Reynolds number, the hydraulic diameter $\mathrm{D}_{\text {he }}$ of the channel inlet cross section, to express the average heat transfer coefficient in dimensionless form, as in below

$$
\overline{\mathrm{Nu}}_{\mathrm{m}}=\frac{\overline{\mathrm{h}}_{\mathrm{m}} \mathrm{D}_{\mathrm{he}}}{\mathrm{k}_{\mathrm{a}}}
$$

\section{RESULTS}

The numerical results obtained for the average Nusselt number for the investigated channels were expressed as functions of the Reynolds number Re to compare the thermal behavior of the channels with distinct sizes, opening widths, and mass flow rates. Figure (5-a) presents the numerical results for channels I, II and III under distinct flow rates with the inlet cross section fully open $(\mathrm{t} / \mathrm{L}=1)$. Figure (5b) shows the influence of the inlet width ratio $(\mathrm{t} / \mathrm{L})$ on the results for channel I.

As seen in Figure (5-a), the results for the channels I, II and III, considering $(\mathrm{t} / \mathrm{L}=1)$ are represented by three distinct curves, showing an increase of $\overline{\mathrm{Nu}}_{\mathrm{m}}$ with the air flow rate. For a specified value of $\mathrm{Re}$, there is a decrease of $\overline{\mathrm{Nu}}_{\mathrm{m}}$ from channel I to channel III, but the results for channels I and II are closer to each other than to the results for channel III.

Comparing their sizes, it is observed that the fins aspect ratio $(\mathrm{s} / \mathrm{H})$ of the fins spacing $\mathrm{s}$ to their height $\mathrm{H}$ also decreases from channel I to channel III. Similarly, to the values of $\overline{\mathrm{Nu}}_{\mathrm{m}}$, the values of $(\mathrm{s} / \mathrm{H})$ for channel I (0.167) and channel II (0.160) are also relatively closer to each other than that of channel III $(0,120)$. Thus, the fins aspect ratio $(\mathrm{s} / \mathrm{H})$ was considered an important dimensionless parameter to evaluate the average Nusselt number.

Figure (5-b) presents distinct results for a single channel with four distinct values of the opening width ratio $(\mathrm{t} / \mathrm{L})$.For a specific value of $\mathrm{Re}$, these results show an evident increase of $\overline{\mathrm{Nu}}_{\mathrm{m}}$ with the ratio $(\mathrm{t} / \mathrm{L})$.Thus, this was considered another important dimensionless parameter to evaluate the average Nusselt number $\overline{\mathrm{Nu}}_{\mathrm{m}}$.

A third dimensionless geometric parameter considered important was the same considered by Biber (1997), that is, the dimensionless channel length $\left(\mathrm{L} / \mathrm{D}_{\mathrm{hs}}\right)$, associated to the channel hydraulic diameter $\mathrm{D}_{\mathrm{hs}}=2 \mathrm{Hs} /(\mathrm{H}+\mathrm{s})$ at its outlet cross section. This dimensionless channel length decreases from channel I to channel III, with values respectively equal to 5.833, 3.625 and 2.334 , presenting a similar trend of decrease of the average Nusselt number observed in Figure (4a).

A correlation based on the product of the considered dimensionless parameters, each one to the 
power of a constant coefficient was considered in the form indicated by Eq. (19).

From the results of all the numerical modeling performed, the constant $\mathrm{A}$ and the exponents $\mathrm{B}, \mathrm{C}, \mathrm{D}$ and $\mathrm{E}$ were obtained by the method of least squares applied to a total of 77 simulations of the seven isothermal channels, under the restrictions that the constant A should be equal to one and that the exponent $\mathrm{B}$ in the general correlation should be equal to 0.5 . These restrictions were imposed after initial evaluations of the general correlation indicated that these two constants were good approximations to the values generated by the least squares' method. The result for the final correlation was expressed by Eq. (20).

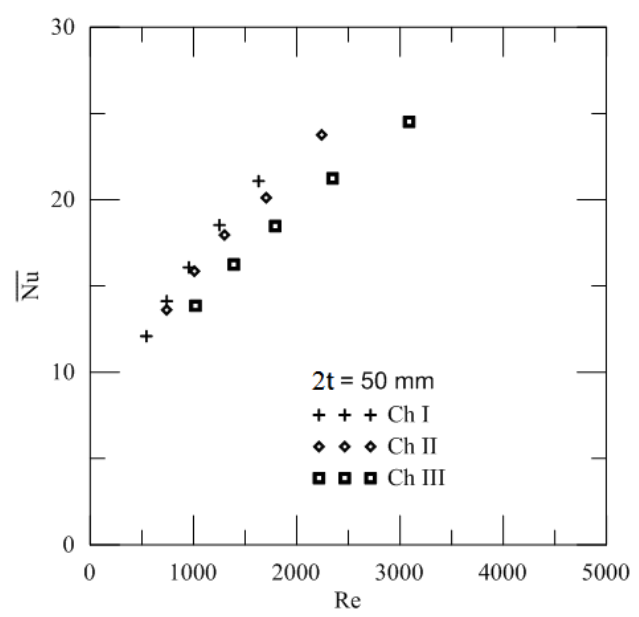

(a)

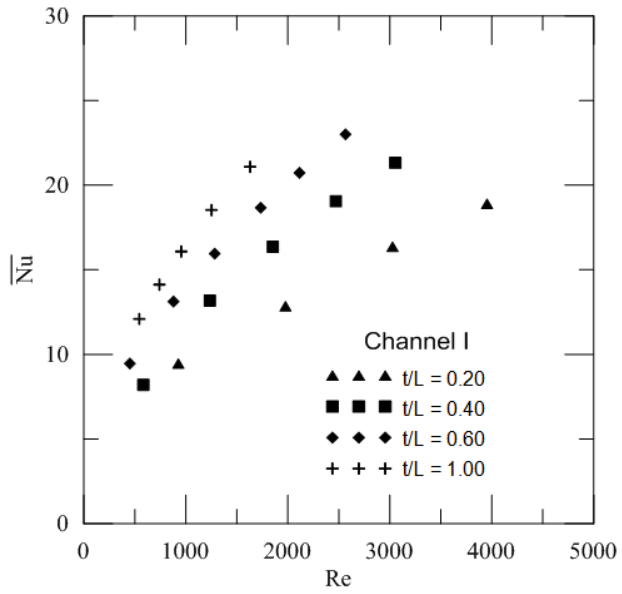

(b)

Figure5. (a) Average Nusselt number for channels I to III with $\mathrm{t}=50 \mathrm{~mm}$ and (b) the effect $(\mathrm{t} / \mathrm{L}$ ) on the average Nusselt number for channel I. Source: authors, 2019.

$$
\begin{gathered}
\overline{N u}_{m}=\operatorname{ARe}^{B}\left(\frac{s}{H}\right)^{C}\left(\frac{t}{L}\right)^{D}\left(\frac{L}{D_{h e}}\right)^{E} \\
\overline{N u}_{m}=\operatorname{Re}^{0.5}\left(\frac{s}{H}\right)^{0.47}\left(\frac{t}{L}\right)^{0.36}\left(\frac{L}{D_{h e}}\right)^{0.13}
\end{gathered}
$$

With the same approach presented above, a pressure loss coefficient was proposed through numerical simulations and it is in form of Eq. (21).

$$
K=\operatorname{Re}^{-0,24}\left(\frac{\mathrm{S}}{\mathrm{H}}\right)^{-0,96}\left(\frac{\mathrm{t}}{\mathrm{L}}\right)^{1,8}\left(\frac{\mathrm{L} / 2}{\mathrm{D}_{\mathrm{he}}}\right)^{1,8}
$$

The validity of the proposed correlation is limited by the range of parameters associated to the testes heat sinks I to VII. The dimensionless geometric parameters were within the following ranges: $0.07<(\mathrm{s} / \mathrm{H})<0.17,0.11<(\mathrm{t} / \mathrm{L})<1.0$ and 2.33 $<\left(\mathrm{L} / \mathrm{D}_{\mathrm{he}}\right)<5.83$. The simulations were also limited to a range of the Reynolds number within $500<\mathrm{Re}$ $<7000$.

Experimental data was obtained with a heatsink of dimensions 900x900x12 mm. The average spacing between fins is $2.2 \mathrm{~mm}$. Three different openings were tested with several mass flow values. Results presented in Figs. 6 (a-c) show good agreements with the proposed correlation, indicating 6 to $7 \%$ of uncertainty associated with experimental data and $14 \%$ as the higher deviation from proposed correlation with experimental data.

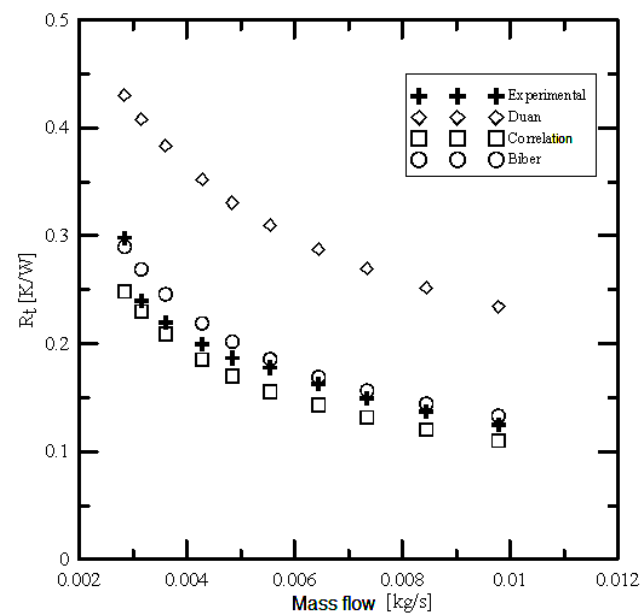

(a)

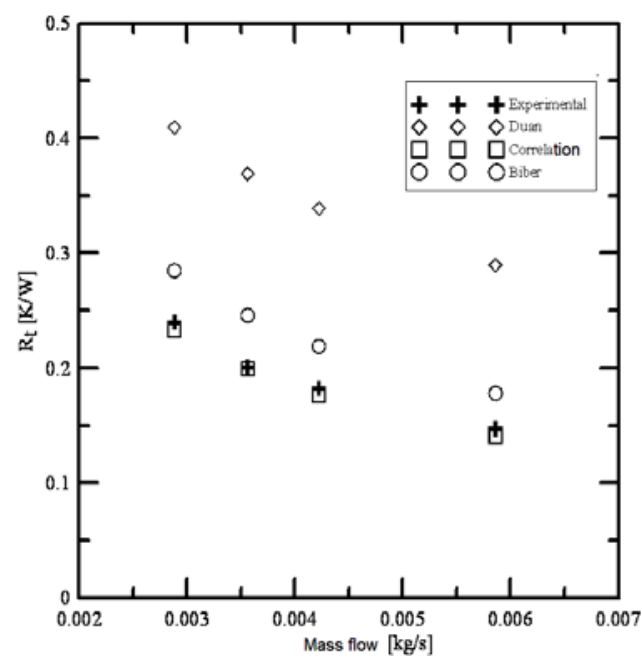

(b) 


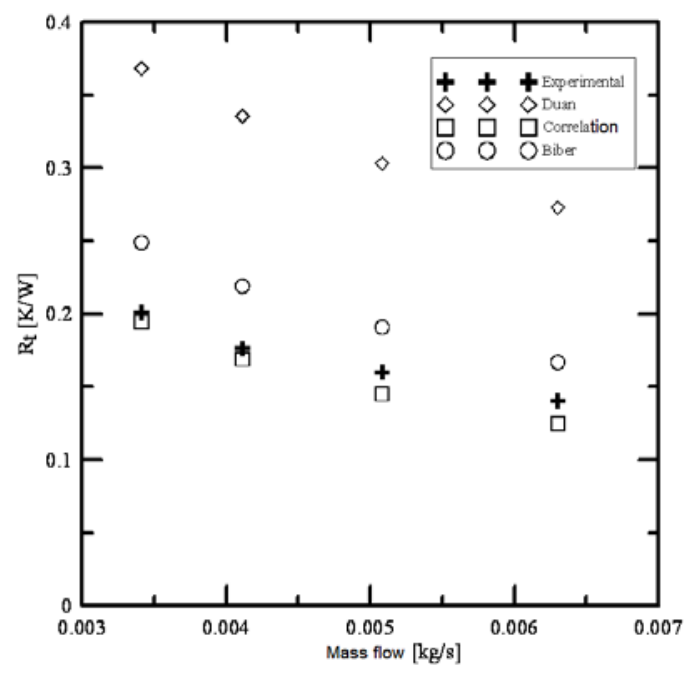

(c)

Figure 6. Comparison with experimental data: (a) 40 mm opening, (b) $20 \mathrm{~mm}$ opening and (c) $10 \mathrm{~mm}$ opening. Source: author, 2019.

\section{CONCLUSIONS}

A correlation for the average Nusselt number in channels of parallel plates heat sinks with TISE configuration was proposed, in terms of the inlet flow Reynolds number and three geometric parameters of the heat sinks: the fins aspect ratio $(\mathrm{s} / \mathrm{H})$, the inflow relative opening $(\mathrm{t} / \mathrm{L})$ and the dimensionless length $\left.(\mathrm{L}) / \mathrm{D}_{\text {he }}\right)$ The correlation was based on the numerical results of the simulations of seven distinct fins channels.

\section{ACKNOWLEDGEMENTS}

The authors acknowledge CNPq, Unesp, UNICAMP and UFOB for the support provided.

\section{REFERENCES}

Arik, M., 2013, Steady and Unsteady Air Impingement Heat Transfer for Electronics Cooling Applications, Journal of Heat Transfer, Vol. 135, No. 11.

Biber, C. R., 1997, Pressure Drop and Heat Transfer in an Isothermal Channel with Impinging Flow, IEEE Transactions on Components, Packaging, and Manufacturing Technology: part A, Vol. 20, No. 4.

Cheng, H., 2010, An experimental and computational study of water cooled heatsinks for HEV's, Institution of Engineering and Technology.

Colla, L., 2017, Nano-Phase Change Materials for Electronics Cooling Applications, Journal of Heat Transfer, Vol. 139, No. 5.

Daliang, Z., 2010, Thermal Performance of Heatsink and Thermoelectric Cooler Packaging Designs in LED, IEEE.

Duan, Z., and Muzychka, Y. S., 2006, Experimental Investigation of Heat Transfer in
Impingement Air Cooled Plate Fin Heat Sinks, Journal of Electronic Packaging, Vol. 128, No. 4, pp. 412.

Fabbri, M., and Dhir, V. K., 2005, Optimized Heat Transfer for High Power Electronic Cooling Using Arrays of Microjets, Journal of Heat Transfer, Vol. 127, No. 7.

Issa, J. S., and Ortega, A., 2002, Experimental Measurements of the Flow and Heat Transfer of a Square Jet Impinging on an Array of Square Pin Fins, ASME, pp. 179-193.

Jonsson, H., and Moshfegh, B., 2001, Modeling of the Thermal and Hydraulic Performance of Plate Fin, Strip Fin, and Pin Fin Heat Sinks-Influence of Flow Bypass. IEEE Transactions on Components and Packaging Technologies, Vol. 24, No. 2, pp. 142-149. Kotlar, A., and Svasta, P., 2017, Cooling Method for High Power Dissipation SMD Packages, IEEE, pp. 1-4.

Moffat, R. J., 2007, Modeling Air-Cooled Heat Sinks as Heat Exchangers, IEEE.

Nonneman, J., 2018, Model-Based Comparison of Thermo-Hydraulic Performance of Various Cooling Methods for Power Electronics of Electric Vehicles, IEEE.

Saffaripour, M., and Culham, R., 2010, Measurement of Entropy Generation in Microscale Thermal-Fluid Systems, Journal of Heat Transfer, Vol. 132, No. 12, pp. 121401.

Souza, V. C., 2005, Dissipadores Térmicos de Placas Paralelas com Influxo de Topo, Doctoral Thesis, Universidade Estadual de Campinas, Faculdade de Engenharia Mecanica, Campinas, SP. (in Portuguese).

Teertstra, P., and Yovanovich, M. M. R., 2000, Analytical Forced Convection Modeling of Plate Fin Heat Sinks, Journal of Electronics Manufacturing, Vol. 10, No. 4, pp. 253-261.

Wada, M., 2017, Feasibility Study of two-Phase Immersion Cooling in Closed Electronic Device., IEEE, pp. 899-904.

Webb, R. L., 2017, Heat Exchanger Design Methodology for Electronic Heat Sinks, Journal of Heat Transfer, Vol. 129, No. 7, pp. 899.

Zhu, Q., 2017, Thermal Characterisation of a Copper-Clip-Bonded IGBT Module with DoubleSided Cooling, IEEE, pp. 1-6. 